\title{
DESEMPENHO REPRODUTIVO DE PORCAS E PRODUTIVO DE LEITÕES DESMAMADOS AOS 14 E 21 DIAS DE IDADE
}

\author{
OSTE, Renata Luiza de ${ }^{1}$ \\ MELLO, Silvio de Paula ${ }^{2}$
}

Recebido em: 2009-02-17

Aprovoado em: 2009-04-29

ISSUE DOI: $10.3738 / 1982.2278 .170$

RESUMO: O experimento foi conduzido na Faculdade Dr. Francisco Maeda - FAFRAM, localizada no município de Ituverava-SP, situada a $20^{\circ} 20^{\prime} 30^{\prime \prime}$ de latitude S e $47^{\circ} 47^{\prime} 30^{\prime \prime}$ de longitude O e altitude de 631 metros, no período de 18 de fevereiro de 2008 a 30 de maio de 2008, com o objetivo de avaliar o desempenho dos animais do nascimento aos 60 dias de idade e o retorno ao cio das matrizes submetidas a diferentes idades de desmame. Os dados coletados foram submetidos a análise de variância e comparação das médias pelo teste de Tukey, tendo-se estabelecido o nível de $5 \%$ de possibilidade de erro (95\% de confiabilidade) para aceitação dos resultados. Pôde-se concluir que os animais desmamados com 14 e 21 dias tiveram resultados semelhantes nas características avaliadas, não prejudicando o seu desempenho. As porcas manifestaram cio logo após o desmame, sendo que também não foram influenciadas pela data do desmame.

Palavras - Chave: Suíno. Desmama precoce. Reprodução de porcas.

\section{REPRODUCTIVE PERFORMANCE OF SOWS AND PRODUCTION OF WEANERS AT 14 AND 21 DAYS OF AGE}

SUMMARY: The experiment was made in the college "Dr. Francisco Maeda - FAFRAM", situated in ItuveravaSP and its geographical coordinates are latitude of 20²0'30" South, longitude $47^{\circ} 47^{\prime} 30^{\prime}$ " West and 631 meters of elevation, since February 18 up to May 30, 2008. Its goal is evaluating the performance of animals since their birthday up to 60 days of life and about the period of time that the female reproducer animal, which is submitted to stop suckling in different periods of time, takes to have a new fertile period. The collected data were analyzed into two aspects: variance and comparison of the means using the Turkey test, the possibility of error was set 5\% ( $95 \%$ of reliability) to have acceptable results. It concluded that the animals which stopped suckling in 14 or 21 days showed similar results in the evaluated aspects and it means that their performance was not impaired. The female pigs had fertile period as soon as they stopped suckling and they were not influenced by the day of stopping suckling.

Keyword: Swines. Precocious weaning. Reproduction of sows.

1 Acadêmica do Curso de Medicina Veterinária da FE/FAFRAM - email: reluoste@yahoo.com.br

2 Professor Dr. em Genética e Evolução (UFSCar) - FE/FAFRAM - email: spmello@feituverava.com.br

Nucleus Animalium, v.1, n.1, maio 2009 


\section{INTRODUÇÃO}

A suinocultura possui papel de destaque no contexto nacional, com um grande número de produtores envolvidos, gerando um elevado volume de empregos diretos e indiretos. Além disso, apresenta alta capacidade de produzir proteína de qualidade, num reduzido espaço físico, em curto tempo, quando comparada a outras espécies animais. O desenvolvimento da suinocultura constitui-se em importante fator do desenvolvimento econômico nacional, provocando efeitos multiplicadores de renda e emprego em diversos setores da economia, intensificando a demanda de insumos agropecuários e a expansão e modernização dos setores de comercialização e agroindústrias (ASSIS, 2006).

Orebanho suíno brasileiro tem sua maiorrepresentaçãonumérica, econômica e tecnológica na Região Sul (ABCS, 1999), o que fundamenta o desenvolvimento rentável da produção animal nesta região em produtividade e qualidade dos produtos. A moderna suinocultura, como atividade zootécnica, é voltada à adoção de técnicas que viabilizam a atividade e preconizam o melhor desempenho produtivo dos animais. O peso dos leitões ao nascimento, ao desmame e os ganhos diários de peso neste período estão diretamente relacionados ao desenvolvimento futuro desses animais, sendo importante considerarem as informações ligadas aos fatores que influenciam estas características, para se maximizar os resultados da atividade (SOUZA et al., 2004).

A redução do período de aleitamento, prática que visa elevar o número de partos por porca por ano, com considerável redução no custo de produção, tornou-se grande desafio para os nutricionistas, pois para efetuá-las com eficiência é necessário o estabelecimento de combinação

perfeita de ingredientes, bem como o conhecimento da biodisponibilidade dos nutrientes, de modo a reduzir ou evitar problemas pós-desmame (TRINDADE NETO et al., 1994), tendo-se em vista que o sistema digestivo do leitão recém nascido está naturalmente adaptado ao leite da porca, e a troca deste alimento por outro alimento ou outro sistema de alimentação, no caso de desmame precoce, pode associar-se a distúrbios gastrointestinais e depressão no crescimento (LOPES et al., 1994).

Em qualquer idade, o processo de desmame é extremamente difícil para o leitão. Além da perda do contato com a porca, ocorrem outros fatores estressantes, tais como: troca da alimentação (passando do leite a uma ração sólida), e supressão da imunidade passiva (perda da proteção de anticorpos proporcionada pela ingestão do leite), troca de ambiente (mudança da cela parideira para boxes ou gaiolas de creches), tensões sociais (resultantes do reagrupamento após o desmame), dificuldade de adaptação com cochos e bebedouros, alojamento em instalações com deficiência no controle ambiental (manutenção de temperatura, umidade e ventilação) (FERREIRA; SOUSA, 2008).

A tentativa de minimizar todos esses fatores pode significar a diferença entre o sucesso ou o fracasso no crescimento durante o período pós desmame. O desenvolvimento do leitão nessa fase é fundamental, pois, se não ganhar peso rapidamente nessa idade, tende a ter o crescimento 
retardado para todo o resto do período de crescimento e engorda. (SOBESTIANSKY et al., 1998)

O objetivo deste trabalho foi avaliar o desempenho dos animais do nascimento aos 60 dias de idade, submetidos a duas idades de desmame (14 e 21 dias) e retorno ao cio de matrizes.

\section{MATERIAL E MÉTODOS}

O experimento foi conduzido no setor de suinocultura da Faculdade Dr. Francisco Maeda - FAFRAM (Figura 1), localizada no município de Ituverava-SP, situada a $20^{\circ} 20^{\prime} 30^{\prime}$ " $\mathrm{S}$ e $47^{\circ} 47^{\prime} 30^{\prime \prime}$ W e altitude de 631 metros, no período de 18 de fevereiro de 2008 a 30 de maio de 2008.

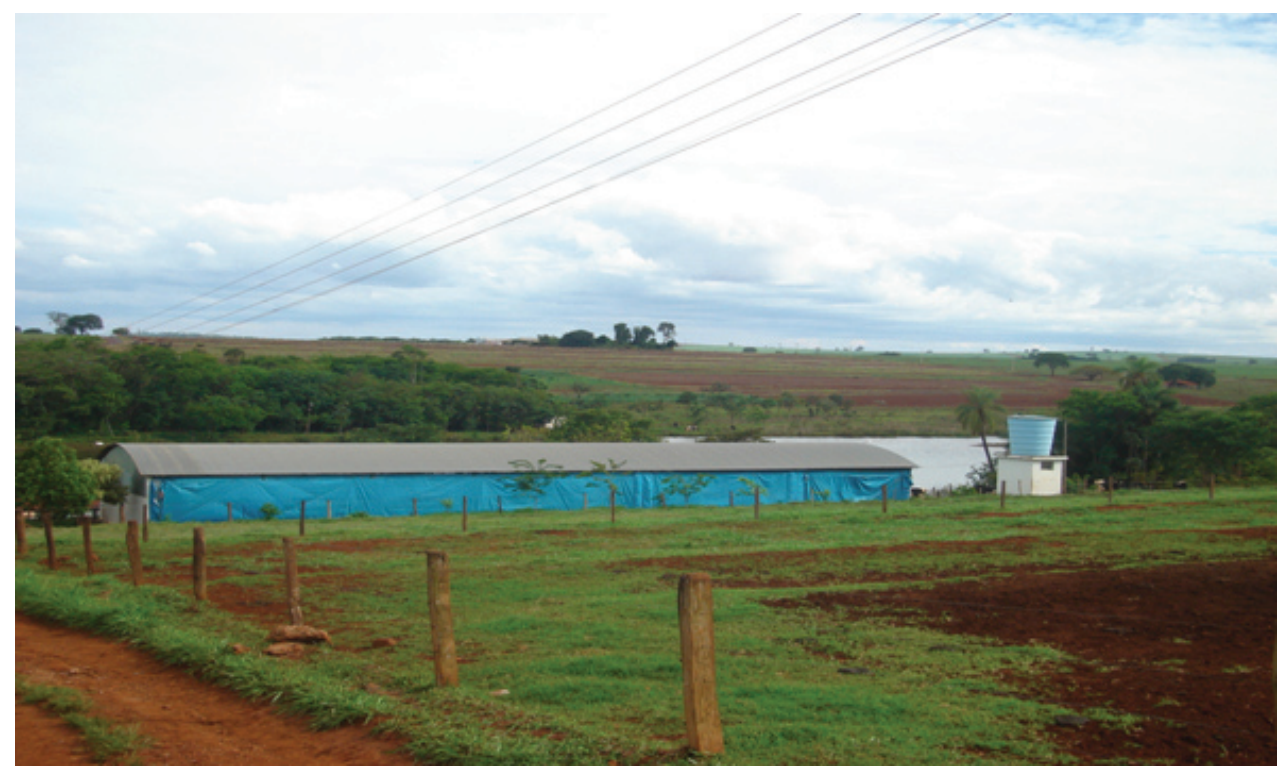

Figura 1 - Setor de Suinocultura da FAFRAM

Foram utilizados 56 animais da raça Landrace desmamados em diferentes idades de desmame, com 14 e 21 dias, divididos em dois grupos. Todos os leitões ficaram no berçário, até o desmame que ocorreu com 14 e 21 dias. Após o desmame os leitões foram transferidos para a creche, aonde permaneceram até 60 dias.

Durante o experimento os animais foram pesados: ao nascimento, ao desmame e aos 60 dias de idade, identificados de acordo com os grupos experimentais. Todas as medidas profiláticas (vacinação, desinfecção das instalações, etc.) foram realizadas durante o experimento.

Os animais foram avaliados na fase de berçário (Figura 2) e creche (Figura 3), sendo que após as pesagens mensais dos animais foram determinados os ganhos de peso e o ganho médio diário dos animais. 


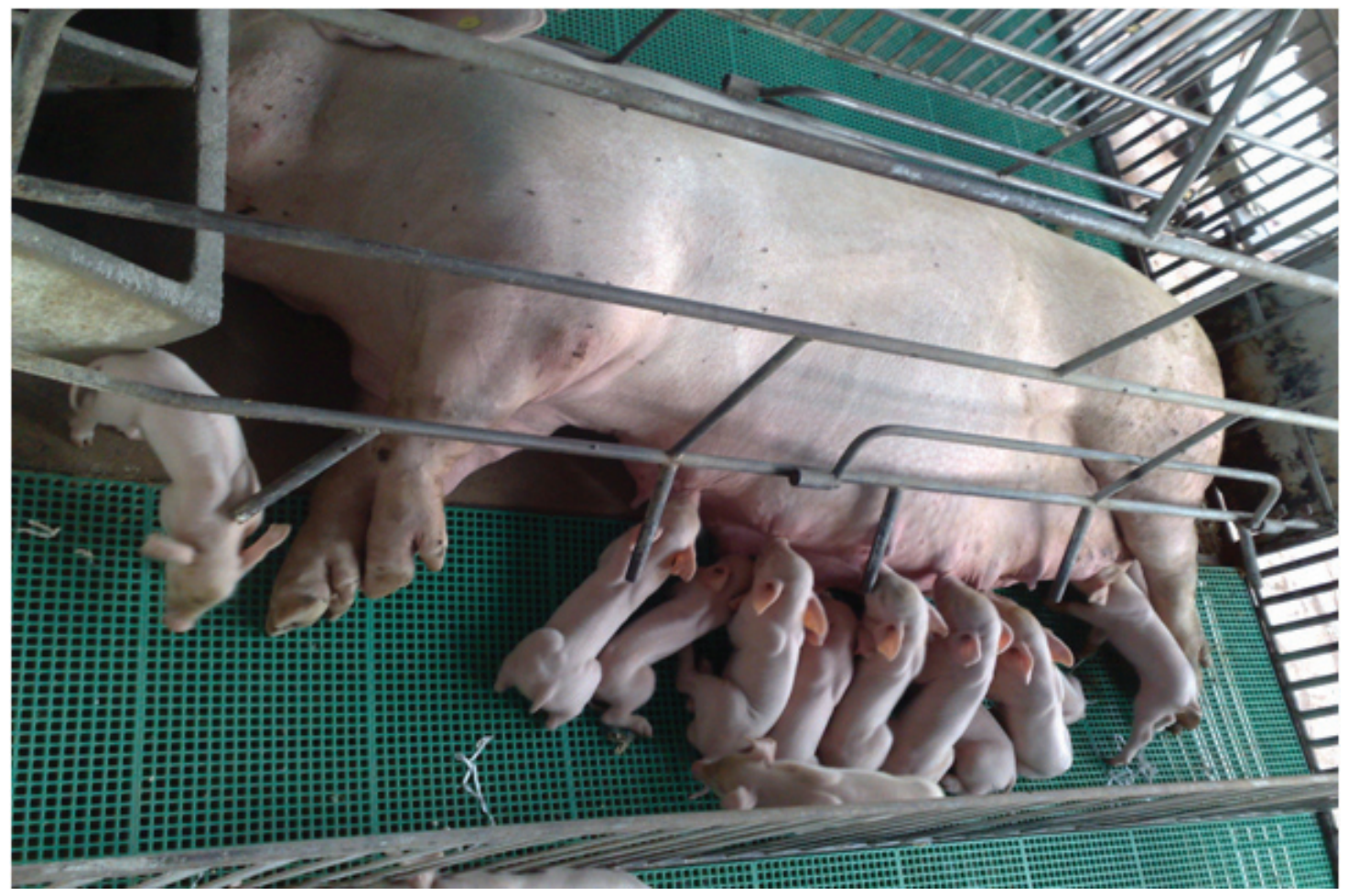

Figura 2 - Fase de Berçário

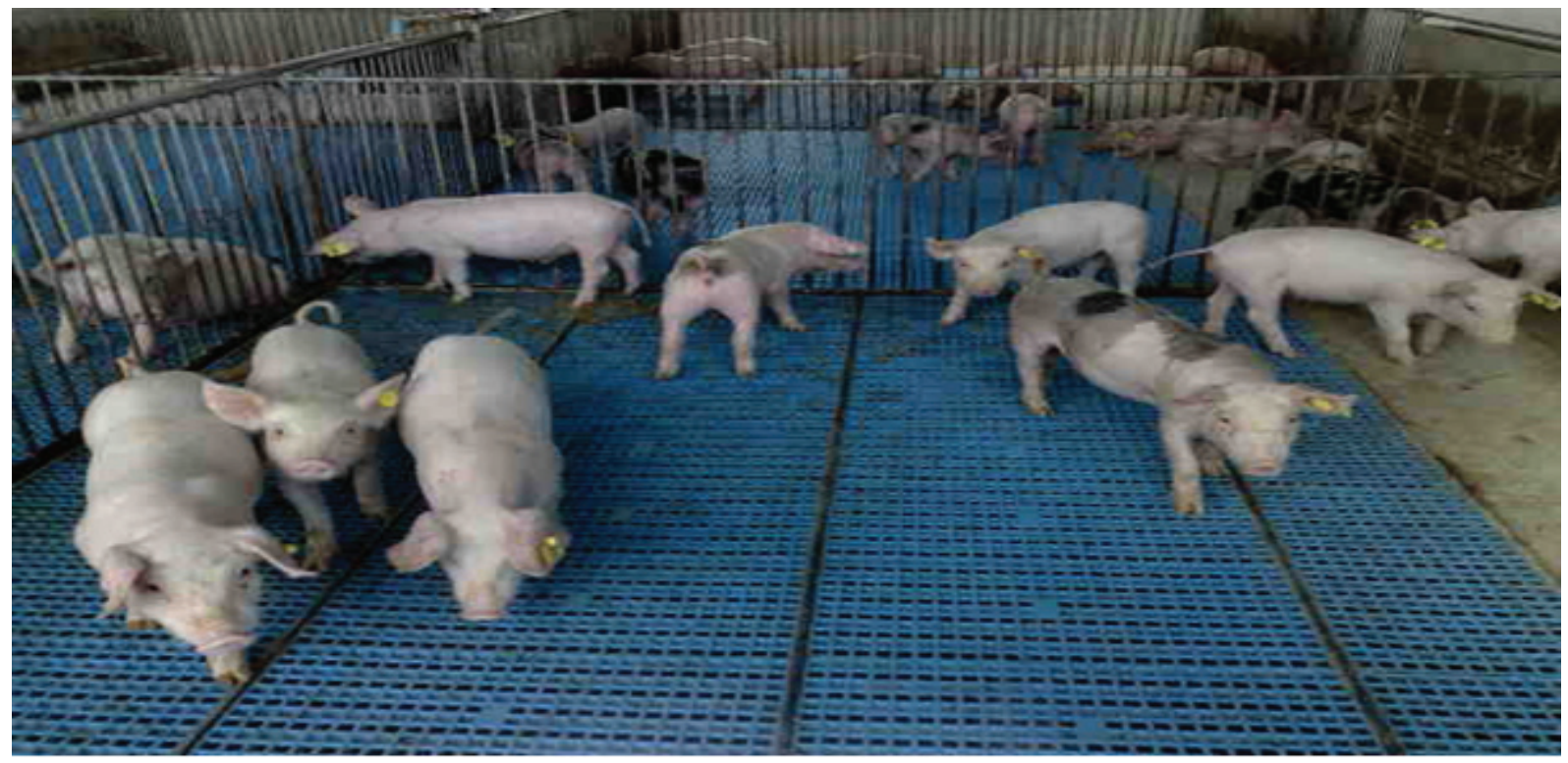

Figura 3 - Fase de Creche

No experimento, a ração foi fornecida à vontade, para que pudesse ter sempre alimento no comedouro. A composição da ração utilizada nas diferentes fases de criação dos suínos foi a base de milho, farelo de soja e premix mineral e vitamínico, atendendo as exigências nutricionais de todos as fases de criação. As dietas foram formuladas de acordo com as exigências do NATIONAL RESEARCH COUNCIL (1998) e foram fabricadas nas dependências do setor de suinocultura da Faculdade Dr. Francisco Maeda - FAFRAM.

As características analisadas foram: peso ao Nascimento (PN), peso ao desmame (PD), 
peso aos 60 dias (P60), ganho de peso do nascimento ao desmame (GPND), ganho de peso do nascimento aos 60 dias de idade (GPN60), ganho de peso do desmame aos 60 dias de idade (GPD60) e os ganhos médios diário do nascimento ao desmame (GMDND), do nascimento aos 60 dias de idade (GMDN60) e do desmame aos 60 dias de idade (GMDD60). Também foi avaliado o retorno ao cio, em dias, das matrizes submetidas a diferentes idades de desmame.

$\mathrm{O}$ delineamento experimental utilizado foi o delineamento inteiramente casualizado (DIC), com dois tratamentos (diferentes idades de desmame).

Os dados coletados foram submetidos a análise de variância e comparação das médias pelo teste de Tukey, tendo-se estabelecido o nível de 5\% de possibilidade de erro $(95 \%$ de confiabilidade) para aceitação dos resultados.

\section{RESULTADOS E DISCUSSÃO}

Os valores médios das características avaliadas encontram-se na Tabela 1. Verifica-se que os pesos ao nascimento (PN), aos 60 dias de idade (P60), o ganho de peso do nascimento (GPN60) aos 60 dias de idade, ganho de peso do desmame (GPD60) aos 60 dias de idade, apresentaram diferença significativa. Já para o peso ao desmame (PD) e ganho de peso do nascimento ao desmame (GPND) não foi verificado significância.

As médias para o peso ao desmame (PD) foram de 6,31 $\mathrm{kg}$ e $6,24 \mathrm{~kg}$ para os animais desmamados com 14 e 21 dias, respectivamente, evidenciando que o desmame aos 14 dias não prejudicou o desenvolvimento dos leitões. Para o peso aos 60 dias de idade os leitões apresentaram médias de 23,52 kg aos 14 dias de idade e 20,13 kg aos 21 dias de idade. O maior peso aos 60 dias de idade dos leitões desmamados com 14 dias de idade, pode ser explicado provavelmente pelo fato da menor concorrência entre os leitões pelo leite materno e consumo mais cedo na ração fornecida aos mesmos ainda na maternidade.

Tabela 1 - Valores médios do PN (Peso ao Nascimento), PD (peso ao desmame), P60 (peso aos 60 dias), GPND (Ganho de Peso do Nascimento ao Desmame), GPN60 (Ganho de Peso do Nascimento até 60 dias de idade) e GPD60 (Ganho de peso do Desmame aos 60 dias de idade) de acordo com a idade ao desmame de suínos da raça Landrace, 2008.

\begin{tabular}{lcccccc}
\hline TRATAMENTO & \multicolumn{7}{c}{ CARACTERÍSTICAS (kg) } \\
\cline { 2 - 7 } & PN & PD & P60 & GPND & GPN60 & GPD60 \\
\hline 14 dias & $1,58 \mathrm{a}$ & $6,31 \mathrm{a}$ & $23,52 \mathrm{a}$ & $4,73 \mathrm{a}$ & $21,94 \mathrm{a}$ & $17,21 \mathrm{a}$ \\
21 dias & $1,26 \mathrm{~b}$ & $6,24 \mathrm{a}$ & $20,13 \mathrm{~b}$ & $4,98 \mathrm{a}$ & $18,87 \mathrm{~b}$ & $13,89 \mathrm{~b}$ \\
Média & 1,43 & 6,28 & 21,95 & 4,85 & 20,51 & 15,67 \\
C.V. & 23,19 & 17,33 & 19,34 & 20,58 & 20,42 & 25,85 \\
\hline
\end{tabular}

Médias seguidas pela mesma letra não diferem significativamente, pelo Teste de Tukey $(\mathrm{P}<0,05)$.

CV - Coeficiente de Variação. 
Segundo Moreira et al., (2001) o peso ao desmame dos leitões aos 21 dias foi $6,03 \mathrm{~kg}$ e de 12,33 $\mathrm{kg}$ aos 50 dias de idade. Os valores encontrados nesse experimento de 6,24 kg aos 21 dias, aos 14 dias de $6,31 \mathrm{~kg}$ para o peso ao desmame foram superiores e para o peso aos 60 dias de idade também foram superiores.

Segundo os dados obtido por Soares et al. (2000), o ganho de peso do nascimento ao desmame foi de $3,84 \mathrm{~kg}$, mostrando-se inferior aos dados relatados neste experimento, mas de acordo com Talarico (2005) o valor encontrado foi de 5,89 kg, superando o valores encontrados nesse experimento.

Os valores do GMDND (ganho médio diário do nascimento ao desmame), GMDN60 (ganho médio diário do nascimento aos 60 dias de idade) e GMDD60 (ganho médio diário do desmame aos 60 dias de idade) de acordo com a idade ao desmame são mostrados na Tabela 2. Os ganhos médios diário do nascimento ao desmame (GMDND) e do nascimento aos 60 dias de idade (GMDN60) apresentaram médias significativas, evidenciando ainda valores médios maiores para os animais desmamados aos 14 dias de idade.

Tabela 2 - Valores médios de GMDND (ganho médio diário do nascimento ao desmame), GMDN60 (ganho médio diário do nascimento aos 60 dias de idade) e GMDD60 (ganho médio diário do desmame aos 60 dias de idade) de acordo com a idade ao desmame de suínos da raça Landrace, 2008.

\begin{tabular}{lccc}
\hline \multicolumn{1}{c}{ TRATAMENTO } & CARACTERÍSTICAS & \\
& GMDND & GMDN60 & GMDD60 \\
\hline 14 dias & $0,31 \mathrm{a}$ & $0,36 \mathrm{a}$ & $0,37 \mathrm{a}$ \\
dias & $0,23 \mathrm{~b}$ & $0,31 \mathrm{~b}$ & $0,36 \mathrm{a}$ \\
Média & 0,27 & 0,33 & 0,36 \\
C.V. & 20,51 & 21,01 & 27,35 \\
\hline
\end{tabular}

Médias seguidas pela mesma letra não diferem significativamente, pelo Teste de Tukey $(\mathrm{P}<0,05)$.

CV - Coeficiente de Variação.

Os ganhos médios diário de $0,31 \mathrm{~kg}$ e $0,23 \mathrm{~kg}$ dos leitões durante a lactação foram superiores aos resultados encontrados por Cota et al., (2003) e Dourmand et al.,(1998), os quais obtiveram respectivamente os valores de $0,188 \mathrm{~kg}$ e $0,196 \mathrm{~kg} / \mathrm{dia}$. Quando comparado com Talarico, (2005) o ganho médio diário do nascimento ao desmame (21 dias) foi de 0,281 kg, mostrando-se próximo do resultado obtido no experimento.

Duarte Júnior (2006) avaliando animais da raça Landrace, encontrou pesos ao desmame de 5,60 kg e 6,45 kg, respectivamente, para animais desmamados aos 14 dias e 21 dias de idade, não apresentando diferenças significativas, estando abaixo dos encontrados nesse trabalho. Aos 50 dias de idade, os valores foram de 14,45 kg e 21,37 kg, para animais desmamados aos 14 e 21 dias de idade, respectivamente, e para o ganho médio diário do nascimento ao desmame foram verificados valores médios de $0,33 \mathrm{~kg}$ e $0,25 \mathrm{~kg}$ para animais desmamados aos 14 e 21 dias de idade, que estiveram próximos aos encontrados nesse experimento. 
As porcas avaliadas nesse experimento apresentaram valores médios, em dias, de retorno ao cio de 5,67 e 6,33, para o desmame efetuado aos 14 dias e 21 dias, respectivamente. Foi verificado portanto, que o desmame com 14 dias não prejudicou o retorno ao cio das matrizes e que pode promover um aumento no número de partos/porca/ano, consequentemente aumentando a lucratividade da criação.

\section{CONCLUSÃO}

De acordo com os dados obtidos, os animais desmamados com 14 e 21 dias apresentaram desempenho semelhantes para as características avaliadas e não prejudicaram o retorno ao cio das matrizes.

\section{REFERÊNCIAS}

ABCS. Suinocultura 500 anos. Estrela: Associação Brasileira dos Criadores de Suínos, 1999. p. 8 .

ASSIS, F.O. Poluição hídrica por dejetos de suínos: um estudo de caso na área rural do município de Quilombo, Santa Catarina. 182 f. 2006. Dissertação (Mestrado em Geografia). Universidade Federal do Paraná.

COTA, T. S. et al. Níveis de lisina em ração de lactação para fêmeas suínas primíparas. R. Bras. Zootec., v.32 n.1 p.115-122, 2003.

DOURMOND, J.Y. et al. Effect of protein and lysine supply on performance, nitrogen balance and body composition changes of sows during lactation. Journal of Animal Science. v.76. p.542-550. 1998.

DUARTE JÚNIOR, A.J. Avaliação do desempenho de animais desmamados com 14 e 21 dias de idade até o abate. 30f. 2006. Trabalho de Conclusão de Curso (Graduação em Agronomia). Faculdade "Dr. Francisco Maeda”. Fundação Educacional de Ituverava.

FERREIRA, R. A.; SOUSA, R.V. O desenvolvimento do sistema imune de leitões e suas correlações com as práticas de manejo. Disponível em: http://www.editora.ufla.br/ BolTecnico/pdf/ bol_46.pdf, Acessado em: 10 dez. 2008. 
LOPES. P. S.; FREITAS, R. T. F.; FERREIRA, A. S. 1994. Melhoramento de suínos. Viçosa: UFV. 1994. p.39.

MOREIRA, I. et al. Utilização da farinha pré-gelatinizada de milho na alimentação de leitões na fase de creche. Digestibilidade e desempenho. R. Bras. Zootec. v. 30, n. 2, p.440-448, 2001.

NATIONAL RESEARCH COUNCIL. Nutrient requeriments of swine. 10th ed.

Washington: National Academy Press, 1998.

SILVA, C. A. et al. Farelo de girassol na alimentação de suínos em crescimento e terminação: digestibilidade, desempenho e efeitos na qualidade de carcaça. R. Bras. Zootec. v.31, n.2, p.982-990, 2002. (Suplemento).

SOARES, J. L. et al. Soja integral processada (Fermentada e extrusada) e farelo de soja em substituição ao leite em pó em dietas de leitões desmamados aos 14 dias de idade. R. Bras. Zootec.,Viçosa: UFV, v.29, n.4, jul./ago. 2000.

SOBESTIANSKY, J. et al.(Ed). Suinocultura intensiva: produção, manejo e saúde do rebanho. Brasília: EMBRAPA-SPI, 1998. p.135-160.

SOUZA, J. C. et al. Estudo do peso ao nascimento, desmame e ganho de peso de suínos criados no Oeste do Estado do Paraná. Revista Acadêmica: ciências agrárias e ambientais. Curitiba, v.2, n.1, p. 35-40, jan./mar. 2004.

TALARICO, M.E.S. Influência da raça paterna no desempenho da leitegada do nascimento até 45 dias de idade. 29p. 2005. Trabalho de Conclusão de Curso (Graduação em Agronomia). Faculdade “Dr. Francisco Maeda”. Fundação Educacional de Ituverava.

TRINDADE NETO, M.A.T.; LIMA, J.A.F.; BERTECHINI, A.G. Dietas e níveis protéicos para leitões desmamados aos 28 dias de idade - fase inicial. R. Soc. Bras. Zootec., v.23, n.1, p.92-99, 1994.

Nucleus Animalium, v.1, n.1, maio 2009 